\title{
ONTOLOGICAL SHIFT OR ONTOLOGICAL DRIFT: REALITY CLAIMS, EPISTEMOLOGICAL FRAMEWORKS AND THEORY GENERATION IN ORGANIZATION STUDIES
}

\author{
MARK THOMPSON \\ University of Cambridge \\ m.thompson@jbs.cam.ac.uk
}

\begin{abstract}
The author gratefully acknowledges the helpful comments of Martha Feldman, Matthew Jones, Martin Kilduff, Geoff Walsham, and Liz Watson on earlier drafts of this article.

Particular thanks go also to the reviewers for their invaluable insights and continued support throughout the review process.
\end{abstract}


Minor shifts in emphasis between the process and entitative dimensions of management constructs can be an effective method for theory generation. However, such shifts require corresponding adjustments in both ontology and epistemology. Where ontology and epistemology drift out of alignment, there is significant potential for confusion. Four kinds of epistemic-ontological movement are described and illustrated using a range of examples, particularly from the communities of practice literature, and implications discussed for both theory and practice. 
Management scholars differ about the most effective way to develop theory within organizational studies. Perhaps the most obvious debate has been at the level of ontology, between those adopting a structural realist logic relating to an approximate correspondence between knowledge and observable reality, and those who highlight the socially constructed, dynamic and partial nature of knowledge (Hassard, 1993). Both perspectives would appear to be in good health in organization studies: use of structural equation modelling in organizational research, for example, has recently increased (MacCallum \& Austin 2000), whilst qualitative research is now more widely used (Lowe and Gardner 2000) and is no longer questioned by most management scholars (Burgelman 2009).

Scholars subscribing to a more structuralist worldview tend to emphasise the value of enduring models of reality that can be applied across multiple situations. Those subscribing to a more socially constructivist viewpoint tend to emphasise the limitations of such models in engaging accurately with unfolding, often socially inflected, complexity on the ground. As the above exchange in $A M R$ illustrates, positions in this 'paradigm war' can become entrenched. In response, many organization researchers have developed epistemologies that are realist, objectivist, and evolutionary, but which also acknowledge the crucial role played by intersubjective, emergent, and metaphysical factors in shaping organizational reality (McKelvey, 2003). Such constructs are described as 'mid-range' theory (Merton, 1949; Weick, 1989). Mid-range theory acknowledges the importance of abstraction, representation and refinement of general principles that apply across multiple situations, whilst also recognising the limitations of such entitative abstractions in accurately representing emergent, contingent and locally specific reality. Examples of mid-range theory used within organization studies include 
institutional theory (DiMaggio \& Powell, 1983), information theory (Weick, 1969), information diffusion theory (Rogers 1962), role theory (Sarbin 1966), and situated learning theory (Lave \& Wenger 1991).

However, the term 'mid-range theory' masks a range of differences in emphases: some constructs highlight the entitative aspects of a phenomenon, whilst others highlight its more situated, contingent and emergent aspects. Even minor shifts in emphasis in a construct can be helpful in identifying different aspects of a phenomenon, and combining and comparing these different perspectives is often valuable for generating new theory. A clear example is recent developments in our understanding of organizational knowledge, now understood by many as "embrained, embodied, encultured, [and] embedded" - and hence immanent within intersubjective processes - but also "encoded", and reflecting a more explicit organizational reality (Blackler 1995).

These concepts lie in various positions across the spectrum between the traditionally more polarised 'process' and 'entitative' conceptions of organizational knowledge, and their differing positions along the spectrum have enabled a more multifaceted understanding of the phenomenon under study. Similar multifaceted approaches to organizational knowledge that combine elements of entitative and process thinking include conceptions of knowledge as "the residue of thinking" (McDermott 1999:105), a phenomenological emphasis on the process of "knowing" (Blackler 1995) and a conception of the organization itself as a distributed knowledge system (Tsoukas 1996). In turn, these enhanced perspectives have fed through to the practitioner literature (e.g. Von Krogh, Ichijo, \& Nonaka, 2000; Davenport \& Prusak 2000). 
This paper seeks to build a deeper understanding of how scholars can consciously use relatively minor alterations in ontological emphasis such as those described above to enable a creative process of generating mid-range theory. However, it also focuses on the importance of supporting such shifts in ontological emphasis with a consistent shift in epistemological framework. In other words, it demonstrates the negative effect on construct clarity that can occur where epistemology and ontology 'drift' out of alignment with one another such that entities are discussed as if they were processes, and processes are discussed as if they were entities.

For example, when discussing the more explicit, encoded aspects of organizational knowledge, a representational epistemology should be used that is consistent with a discussion of stable entities at the ontological level. Here, concepts such as documented routines, information, data, knowledge capture, and codification are appropriate; using concepts such as 'practice', 'identity', and 'power', borrowed from more process-oriented thinking, would make for an unclear discussion. Similarly, approaching the more tacit, embrained/embodied aspects of knowledge, such has been identified as important in generating social capital (Adler \& Kwon, 2002), requires engaging with something more subjective that emerges through activity and over time. Here, an epistemology is required that is capable of engaging with aspects of dynamic process at the ontological level, such as 'practice', 'identity', and power' - and discussion of documented routines, information, data, knowledge capture, and codification is confusing in this context - although there is ample evidence that this happens (e.g. Pugh \& Dixon 2008). 
The argument is organized into three parts. The first part describes in greater detail how process worldviews differ from their historically more mainstream entitative counterparts. It outlines the great importance of maintaining epistemological and ontological alignment during the alterations in emphasis from one to the other that take place within mid-range theory. Changes in ontological emphasis that maintain epistemic-ontological alignment are termed 'ontological shift', and are considered to maintain the integrity of a construct; those changes where such alignment is not maintained, and the construct is considered to have been compromised, are termed 'ontological drift'. The second part illustrates the significance of the argument through a detailed empirical example of the evolution over time of the "community of practice' construct (Lave \& Wenger 1991), in which examples of both ontological shift and drift are visible. The community of practice literature is a valuable case study in this regard, since it exemplifies mid-range theory in which constructs have undergone successive changes in emphasis, in this case from an initially process-oriented towards a progressively more entitative worldview. The third part provides a discussion of the implications of the concepts of ontological shift and drift for organizational theory-building and practice.

\section{BACKGROUND TO KEY CONCEPTS}

\section{Process and Entity}

The relationship between the notion of a thing, or 'entity' (stable, solid, bounded, controllable) and a process (unstable, fluid, emergent, elusive) is one of the oldest philosophical debates known to humankind, in which the "ruling tradition" is "the Platonic and Aristotelian 
belief that fixity is a nobler and worthier thing than change" (James 1909, in Tsoukas \& Chia 2002: 569). In a clear and illuminating essay, Chia (1997), a leading exponent of processoriented management studies, traces the roots of this ruling tradition in the Greeks' ontological commitment to the unitary, permanent and unchangeable reality of Parmenides, in which entities are primary to process: it is things that change.

Within the field of management, mid-range theory has been developed by scholars adopting primarily entitative, as well as scholars adopting primarily process-oriented, worldviews. More entitative approaches to theorising about organizations are exemplified by the Aston group (e.g. Pugh, Hickson \& Hinings, 1986), which sought to build mid-range theory around the principle of classification of similarities and differences between organizations. As Chia (1997) points out, the resulting systems view, in which organizations are viewed as distinct entities, has been influential within mainstream organizational thought, and forms the dominant approach within a range of organizational studies, including textbooks (e.g. Wilson \& Rosenfeld, 1990; Donaldson, 1996).

In contrast, the process viewpoint takes the view that apparently stable entities are in fact more accurately viewed as unfolding processes ('you never step in the same river twice'). Because this may be less familiar, a short explanation of this viewpoint is offered below. Process-oriented theorists argue that if we build theory about what happens to things, it becomes difficult to appreciate processes in which the 'thing' and the 'happening' are collapsed into a single becoming (e.g. Tsoukas 1996, Feldman 2000, Chia 2002, Sturdy 2003, Carlsen 2006). 
An associated literature has also developed concerned with the co-constitution of human agency and social factors in unfolding 'practices' (for a review, see Schatzki 2001).

A useful introduction to the value of process thinking for management scholars who may be unfamiliar with its full implications is Bakken and Hernes' (2006) paper entitled 'organizing is both a verb and a noun', which proposes that researchers should be cutting verbs and nouns from the same cloth (2006: 1602). In illustrating the co-constitution of verbs and nouns, Bakken and Hernes draw on Von Foerster's example of the 'pseudopod' whereby amoebas or similar unicellular organisms extend temporary projections to propel themselves or engulf food, shown in Figure 1 below:

Insert Figure 1 about here

The above illustration shows various 'snapshots' of the organism in its fluid movement from position/form 1, to position/form 6 . Although we can see six isolable, spatially separate positions during its trajectory - to which we might attach labelling nouns, the pseudopod is always moving. Any representative snapshot taken of the pseudopod at, say position 2 would be an inaccurate representation of the organism, since it bears no relationship to its shape moments later at, say, position 4: the labels are inadequate for describing something that works as a process, since they exist only for a moment. Taking more snapshots in ever finer gradations of atomistic reductionism between these positions would never entirely describe the pseudopod 
either; there would always be fragments of movement that would elude capture by these snapshots. In this example, scholars of organizational process would argue that a noun-based epistemology is profoundly inadequate for engaging with the ontological status of the pseudopod, since it is unable to capture its essence. In contrast, they would claim that the 'essence' of the pseudopod lies in its fluidity - for which it is necessary to combine a physical dimension (noun) with a temporal dimension (verb). The pseudopod exists, and should be discussed, within both dimensions.

Scholars adopting a strongly process-oriented worldview highlight the shortcomings of the snapshots abstracted from the unfolding process in Figure 1. However, in communicating a sense of the contextually contingent fluidity with which the pseudopod moves, such entitative abstractions remain useful indicators of the manner of the pseudopod's movement, and thus of its nature. In this sense, and returning to the relationship between process and entity, the pseudopod example demonstrates the usefulness of both perspectives in studying different aspects of a phenomenon. By the same token, in organizational studies, we continue to use organograms as convenient, useful representations of organizational structure within mid-range organizational theory, although experience tells us that these entitative snapshots tell us little about what is actually going on, and that these are quickly out of date.

The important point made here is that both entitative and process-oriented perspectives bring valuable attributes to our understanding of the world. Shifting between more processoriented and more entitative perspectives on a phenomenon can generate new theoretical insights providing their respective strengths and limitations are understood. As pointed out by 
Van Maanen, Sorensen, and Mitchell (2007), theorizing always entails trade-offs between simplicity and complexity, originality and semblance, and specificity and generality. When undertaking shifts in ontological emphasis to highlight another dimension of a phenomenon, we are necessarily making a new trade-off between entitative and process perspectives in which one is necessarily emphasised at the expense of the other. Of central importance in this paper is what happens when such shifts take place. The next section seeks to build a detailed understanding of what is involved when such trade-offs occur, and explains how these can be achieved positively, as well as what can happen when entitative and process perspectives become misaligned, and we attribute process-like qualities to entities, and vice versa.

\section{Ontological shift or Ontological drift: Abstraction, Conjunction, Reification and Processification}

Figure 2 sets out a number of important characteristics that mark the differences between a process-oriented and an entitative worldview. More specifically it highlights the characteristics of their respective epistemologies and (top half) and ontologies (bottom half). As has been demonstrated using the examples of organizational knowledge and the pseudopod, a process ontology that sees the world as comprising entity and movement (quadrant 2) requires a more holistic, contingent epistemology capable of engaging with such a worldview (quadrant 1). Figure 2 also illustrates that an entitative ontology that sees the world as made up of more stable, independent structures requires a corresponding 'snapshot epistemology' for which more objective representations are appropriate. For example, if we are describing an ontologically stable entity such as an office block or an explicit, codified piece of information (quadrant 4), 
the epistemological framework in quadrant 3 is more suited. In this way, the pairings of quadrants $1 \& 2$ and $3 \& 4$ show epistemic-ontological alignment.

Further, Figure 2 posits that four different types of epistemic-ontological movement are possible as constructs develop and evolve. The first movement is abstraction - left to right in Figure 2 (quadrants $1 \& 2$ to $3 \& 4$ ), in which, like the pseudopod, a representation is literally 'abstracted' from an ongoing process, in order to give form to the flux of organizational experience. Examples of such a movement include the generation of 'best practice' artefacts from emergent, sociomaterially embedded organizational practice, such as unified modelling in organizational workflow design (Rashid, Masood, \& Weston, 2009), the definition and adoption of common standards to enable supply chain integration (Xu, 2007), and the central role of endorsed standard practices within professions (Mahony 2003). In these examples, the limitations of the abstraction process are acknowledged, within a conscious 'ontological shift' in which the intent is to simplify the complexity of organizational process into an isolable entity, whose simplified properties can then be used to advantage.

Insert Figure 2 about here

The second movement, here termed 'conjunction', is in the reverse direction, right to left in Figure 2 (quadrants $3 \& 4$ to $1 \& 2$ ), and this reversal is reflected in its name, whose Latin root is the literal inverse of abstraction. Conjunction involves an equally conscious shift from a purely 
entitative worldview to one that seeks knowingly to explore the more processual, conjoined dimensions of a construct. A good example of conjunction is Nonaka and Takeuchi's (1995) 'knowledge spiral', which sought to challenge many organizations' assumptions that their knowledge was located primarily in entitative, explicit forms by exploring the tacit processes through which such mainstream knowledge assets are created and refined. When discussing the tacit components of their knowledge spiral - socialisation and internalisation - Nonaka and Takeuchi (1995) are careful to emphasise that organizations require a very different way of conceptualising and treating such tacit components from the ways in which they treat the more explicit, isolable activities of externalising and combining knowledge. Nonaka and Takeuchi's 'knowledge spiral' is in fact an example of a mid-range theory based on a knowing ontological shift back and forth between abstraction and conjunction.

A further, more recent example of ontological shift involving conjunction is the 'strategy as practice' movement (e.g. Whittington 2003; Jarzabkowski \& Spee, 2009) which seeks a view of strategy as 'what people do' (quadrant 2) rather than as an entity such as a strategy document, or roadmap (quadrant 4). In highlighting "the complexity of processes that give rise to a strategy and the political influence of many organizational members in doing so, not only through formal organizational processes but also in their everyday activities" (Johnson, Langley, Melin, \& Whittington, 2007: 6), strategy as practice researchers stress the way that entitative conceptions of strategy can be enhanced through a lens that highlights its enacted, and thus necessarily conjoined, dimensions. The epistemological shift is subtle, however; such a view continues to acknowledge the importance of artefacts such as formal processes and documents in crystallising strategic direction, and thus does not attempt inappropriately to supplant an 
entitative with a process worldview. Strategy as practice appears to be a further good example of the potentially rich potential for theory generation that can be achieved by reframing a previously entitative construct via a conjunctive shift in ontological emphasis.

In addition to the two kinds of ontological shift, Figure 2 shows that two kinds of 'ontological drift' are also possible, in which epistemology and ontology become misaligned with a correspondingly negative effect on the clarity of the construct. One of these, reification, forms the third possible movement in Figure 2, and is a commonly acknowledged fallacy (Lefevbre, 2004, Whitehead, 1925), deriving from the Latin words for 'thing', res, and 'to transform', facere (Douglas, 1986). Reification describes the attribution of entitative existence to processes (quadrants $3 \& 4$ to $3 \& 2$ ) - or transforming a social construct (such as an institution) into a thing with unquestioned, separable ontological existence, and 'phantom objectivity' (Lukács, 1969). Such a fallacy is described as a form of 'ontological drift', as the ontological claims have 'drifted' out of alignment with the appropriate epistemological lens. Various strands of institutional theory (e.g. Hall \& Taylor, 1996) are indeed definable as conscious attempts to avoid attributing standalone ontological existence to institutions and thus unintentionally reifying them, by being careful to acknowledge their embeddedness in ongoing socio-political-cultural processes.

Avoiding reification is not always easy, however; continuing with institutional theory, for example, there is evidence (Kim 2005) that some theorists have tried to apply an overly static, entitative epistemology (quadrant 3) to understand institutional continuity over time, resulting in epistemic-ontological misalignment and loss of construct clarity. In such cases, an entitative 
focus on constraining structures may appear at first sight more appropriate for explaining continuity - but is actually inappropriate for explaining continuity conceived as emergent process (e.g. March \& Olsen, 1989; North, 1990). In contrast, Kim (2005) advocates an approach that views institutional embeddedness over time as a process of constant change (quadrant 1) - a 'correct' alignment of epistemology and ontology, that is also theoretically generative.

A further example of ontological reification is the apparent transformation undergone by the concept of 'tacit knowledge' amongst a sizeable management audience. Anyone seeking confirmation as to the organizational impact of this debate and conducting a quick internet search on the phrase "knowledge harvesting" will find that this concept has spawned a large industry in itself, and had a major impact on the direction of many organizations' knowledge and training programs: a particularly marked example of this is the National Health Service in the UK, whose online dictionary explains that "Knowledge harvesting is an approach that allows the tacit knowledge or know-how of experts and top performers in an organization to be captured and documented." (NHS 2005). In such cases, 'tacit knowledge' has come over time to represent for many people an entirely different phenomenon at the level of experienced reality, transforming, in this case, from a description of an embodied, lived experience that emerges in practice, to a description of a disembodied entity that can be transferred and stored at will, with associated techniques and methodologies. The implications of such a shift for the way in which organizations should seek to support their knowledge workers are profound. 
The fourth kind of possible movement in Figure 2, termed here 'processification', is the opposite of reification, and is the second kind of ontological drift. Reflecting the derivation of its counterpart reification, processification also derives from its Latin root, in this case the words for 'process', processus, and 'to transform', facere. Processification remains less explored, but like reification is also a fallacy, and describes the attribution of process-like qualities to entities (quadrants $1 \& 2$ to $1 \& 4$ ). This fallacy is potentially more dangerous to practitioners and researchers alike, since in representing things using process terms, organizations may be tempted to believe that their initiatives are more embedded or conjoined with supporting sociocultural processes than they actually are.

An example of the danger of processification is the controversy surrounding the methodology of participative evaluation within development organizations (Cooke \& Kothari 2001). Cooke and Kothari chart the rise to mainstream during the 1990s of 'participative' methodologies that sought to turn previously 'top down' decisions about peoples' futures into 'bottom up', open-ended processes of consultation capable of better engaging with emergent complexity on the ground. In time, the very success of such approaches ensured that these became progressively hardened into standard 'best practice', with the result that at times 'participation' became little more than a required name-check in securing funding. The significance of this controversy lies in the important political connotations involved where something that has undergone 'ontological hardening' into an entity continues to be represented at epistemological level as a process: in Cooke and Kothari's terms, decisions affecting communities are often framed using participative language as if these formed part of an open- 
ended process, when in reality participative activities are translated into pre-authorised categories and targets (ibid., 2001: 27).

Summarising thus far, this paper highlights the way in which the development and evolution of mid-range theoretical constructs over time necessarily involves subtle alterations in emphasis along the process-entity spectrum, that demand close attention to ensuring a continued alignment between epistemology and ontology. A distinction is made between four possible types of such alteration: abstraction, conjunction, reification and processification. Abstraction and conjunction constitute instances of often richly theoretically generative 'ontological shift' where such alignment is maintained. Reification and processification constitute a more problematic 'ontological drift', where epistemology and ontology become 'unmoored' one from the other, resulting in loss of construct clarity. The next section provides an empirical example of all four instances of ontological shift/drift over time within the literature associated with communities of practice, or 'CoPs' (Lave \& Wenger 1991) - a construct that has had a major impact on scholars and organizations alike.

\section{ONTOLOGICAL SHIFT AND DRIFT WITHIN THE COMMUNITY OF PRACTICE CANON}

Stemming from an original, 'ancestor' construct, cognition in practice (Lave 1988), the family of CoP-related constructs includes communities of practice (Lave \& Wenger 1991, Wenger 1998), constellations of practice (Wenger 1998), networks of practice (Brown \& Duguid 2000), collectivities of practice (Lindkvist 2005), inter-organizational communities of 
practice (Moingeon, Quelin, Dalsace, \& Lumineau, 2006), and virtual communities of practice (Dube, Bourhis, \& Jacob, 2006). These apparently similar-sounding constructs are particularly useful for illustrating how the change in perspective described in this article can be both richly generative where an 'ontological shift' is made explicit, as well as confusing in those cases where 'ontological drift' appears to have occurred between the nature of claims about the world and the conceptual lens through which these are discussed.

\section{Methodology: Construct Clarity and Genealogy}

In order to separate these, superficially similar, constructs from one another, Suddaby's (2010, this journal) definition of construct clarity is applied to each construct to identify in each case whether ontological shift or drift has occurred, and to demonstrate any resulting effect this may have had - positive or negative - on theory generation. Suddaby proposes that clear constructs should be first, precisely defined; second, used in a clearly explained and appropriate context; third, draw strength from their location within relevant semantic relationships; and fourth, cohere together in a logically consistent manner. Suddaby's definition is useful for the present purpose, since it invites explicit consideration of the level of epistemic-ontological alignment within a construct. Beginning with ontology, a precise definition of a construct allows the reader to determine whether the claim being made about reality at the ontological level concerns an entity, or a process, or both. Furthermore, the empirical context within which the phenomenon appears to be located provides further corroboration of the ontological status of the phenomenon under discussion: for example, whilst tacit knowledge is unlikely to be found in library books, (the context is at odds with the definition), we know we are more likely to be on 
the right track if our empirical context lies in observed practice such as managers' application of judgment.

Similarly, analysis of the semantic relationships between a construct and those associated constructs from which it draws theoretical strength is a clear indicator of whether its epistemology is aligned with its ontological claims. For example, Bourdieu's (1977) notion of 'habitus' is likely to offer a more consistent epistemological framework for a discussion of tacit knowledge than cognitive information processing theory (Reiser \& Dempsey, 2007). Finally, Suddaby proposes that "the construct, its definition, its scope conditions, its lineage, and its relationship to other constructs must all make sense" (2010: 351) - in other words, he invites consideration of the coherence of the construct across these dimensions: in the terms used here, the assessment a) of a robust ontology, b) a consistent epistemology, and c) consistent alignment between the two. Suddaby's framework of construct clarity therefore offers an explicit assessment for determining whether, and what type of, ontological shift/drift may have occurred.

The results of such an analysis can then be plotted on a genealogy that exposes differences between epistemological constructs that may on first inspection appear closely related to one another, but which in fact actually rest on very different ontological underpinnings. The concept of genealogy is most associated with Charles Darwin, whose 'Tree of Life' sketch from 'Notebook B' of his voyage on the Beagle, dating from 1837-8 and reproduced at Figure 3. The diagram constitutes the earliest and best known approach to explaining the "transmutation of 
species' in which several differentially related species might evolve over time from a single starting point. The notes read:

Thus between A \& B immense gap of relation. C \& B the finest gradation, B \& D rather greater distinction. Thus genera would be formed. - bearing relation to ancient types with several extinct forms.

Insert Figure 3 about here

Here we have a basic methodology for assessing the degree of relatedness/difference between different organisms of possibly similar appearance. For example, the genealogical differences between various organisms can be set out clearly through use of a taxonomic table. In this instance, Table 1 shows clearly that, although superficially similar, sharks and whales share only one character state, the vertebral column:

Insert Table 1 about here

In Figure 4 below, Carlson (1999) demonstrates the power of phylogenetic trees in laying bare the extent of genealogical difference between apparently similar organisms: in this case, 
although the whale and the shark appear to be closely related, the closest relationship is actually shared between the whale and the human.

Insert Figure 4 about here

This methodology for exposing genealogies of difference between apparently similar organisms is arguably equally useful for exposing differences between apparently similar ideas, such as constructs ending with the '-of practice' suffix. The next section makes use of Suddaby's criteria for construct clarity to assess relative robustness of ontology, consistency of epistemology, and degree of epistemic-ontological alignment between the seven related, apparently similar '-of practice' constructs, displaying these on a similar taxonomic table Table 2 - that exposes their genealogy of difference.

\section{Exposing Ontological Shift and Drift Within the CoP Canon}

Cognition in Practice (Lave, 1988). CoPs arguably have their origin in Jean Lave's Cognition in Practice (1988), a critique of cognitivist anthropology, psychology and sociology, in which she performed a conscious ontological shift of conjunction, arguing that self-contained, entitative notions of individual cognition had no real existence outside of "the whole person in action, acting within the settings of that activity. It is within this framework that the idea of cognition as stretched across mind, body, activity and setting begins to make sense (1988: 18). In response, Cognition in Practice drew on early 'practice theorists' such as Giddens (1979) and 
Bourdieu (1977), outlining a strongly practice-based worldview that corresponds with the characteristics appearing at the 'process' end of the spectrum in Figure 2. At the level of ontology, the definition of the phenomenon under study is a process, the context within which the phenomenon is studied is the 'whole person in action', and at the level of epistemology the construct has semantic relationships with various theories of practice. Table 2 therefore shows the epistemic-ontological alignment of 'cognition in practice' along the process dimension (shown as 'P' to refer to 'process'), and that this therefore be considered an example of theoretically generative ontological shift - from 'person' to 'whole person in action'.

Community of Practice '1' (Lave \& Wenger, 1991). Drawing on and extending this analysis, Lave and Wenger's (1991) seminal book Situated Learning: Legitimate Peripheral Participation described a delicate cognitive dynamic - a process - that they had identified as occurring amongst small groups of artisans. The process describes a virtuous circle where novices begin participating on the periphery of group social interaction and, as they do so, begin to learn and internalise culturally accepted ways of acting within the group. Novices' sustained participation and associated learning about how to behave results over time in their increased proficiency and performance within the group. This increased proficiency leads in turn to their increased motivation and identification with the group itself. Simultaneously, with sustained proficiency and performance comes increased social legitimacy of novices' knowledge claims, as they move in status from newcomers at the periphery of the group towards greater acceptance by, and location within, the core of key members. 
This construct, which Lave and Wenger termed legitimate peripheral participation (LPP), is argued to be a useful way to understand how participation, learning, personal identification, performativity, and social status interact with one another within an unfolding social context. Although Lave and Wenger's core idea (and the title of their book) concerned an unfolding process, they also coined a term to represent any small group of people engaged in this process: community of practice. A key point here is that 'community of practice' is an entity, but it makes sense only as a construct in relation to LPP, a particular, carefully defined process. Table 2 therefore shows that although the notion of a CoP - an entitative term - has been introduced into the construct, the definition of the construct itself remains firmly a process (LPP). Similarly, the context remains that of situated activity - an unfolding process - and the semantic relationships upon which the construct draws are consistently process- and practice- related. In various ways these all investigate cognition/activity and culture as a mutually constitutive dialectic, including those of Bourdieu (1977), Giddens (1979), Engeström (1987), Lave's previous work on practice (1988), Orr (1986) and Wertsch (1985). Situated learning is therefore shown in Table 2 as exhibiting epistemic-ontological alignment and construct coherence, and 'ontological stasis' in that there has been very little movement from Lave's original process-oriented positioning.

Community of Practice '2' (Wenger, 1998). Following on from his 1991 work with Jean Lave, Etienne Wenger published a book in 1998 that sought to flesh out the CoP construct (here termed Community of Practice '2'), and apply it explicitly to the organizational setting. Wenger's book Communities of Practice begins by building on the ontological commitment to process of his work with Lave, drawing on various process-oriented theories of practice, 
meaning, situated experience, subjectivity, and identity (1991: 14). However, the primary focus exhibits a shift away from Lave and Wenger's original dynamic of LPP, a firmly processoriented worldview, to the more entitative construct of the CoPs themselves - those groups of people who may be said to be exhibiting signs of this dynamic. Wenger's book constitutes a shift in focus from the anthropological observation and analysis of localised process, characteristic of his 1991 work with Lave, to architecture of organization-wide generative infrastructure around which it is argued that a similar process may occur. Rather than processes, organizations are now seen as social designs directed at practice (1998: 241).

However, despite the shift of definitional focus onto the CoP construct and shift of context to (similarly entitative) organizational "learning architectures" (1998: 237) Wenger continues to acknowledge the importance of a process dimension within the construct. He does this via a thoughtful discussion of "the concept of reification", defined as "the process of giving form to our experience by producing objects that congeal this experience into 'thingness"' (1998: 58). In particular, a strong link is maintained between the notion of $\mathrm{CoP}$ as reified form, and its underlying generative dynamic, LPP, in which entities and processes are mutually constitutive, comprising a "duality of participation and reification" (1998: 63). For this reason, the definition, context and semantic relationships are all marked as $\mathrm{P} / \mathrm{E}$ (where ' $\mathrm{E}$ ' refers to 'entity') in Table 2, since these all contain an emphasis on both process and entitative dimensions. In this sense, Wenger can be seen to be making a 'playful' ontological shift in the form of a slight abstraction towards the entitative pole of the spectrum in Figure 2, whilst maintaining epistemic-ontological alignment, and construct clarity. 
Wenger's 'playful' reframing demonstrates the capacity of ontological shift to generate thought within the organizational community. Amongst practitioners, major organizations worldwide have launched 'professional community' programmes that aim to replicate the benefits of LPP to serve a range of purposes; although the existence of LPP within such groupings is often not proven, they are often associated with positive benefits (e.g. Lesser \& Storck 2001; Sole \& Edmonsdon 2002; Pan \& Leidner 2003; Garrety, Robertson, \& Badham 2004; Dupouet \& Yildizoglu 2006). Within the management research community, the construct has generated a rich theoretical debate that includes discussion of critical perspectives (Fox 2000; Alvesson \& Willmott 2002; Kimble \& Hildreth 2004) and the potential complexity in the relationship between CoPs and canonical organizational structure (Thompson 2005), as well as CoPs' more mainstream potential as, for example, a valuable professional development tool (Swan, Scarborough, \& Robertson, 2002).

Constellation of practice (Wenger, 1998). As its name implies, the 'constellation of practice' that also appears in Wenger's Communities of Practice is composed of many units of communities of practice, a further shift in entitative focus that is only possible following the first shift. As explained by Wenger:

Some configurations are too far removed from the scope of engagement of participants, too broad, too diverse, or too diffuse to be usefully treated as communities of practice (Wenger 1998: 126-7).

Although, like the CoP, Wenger's 'constellations' construct invokes the '-of practice' suffix, the above definition of constellations of practice shows that these are actually one step removed from actual practice as verifiably experienced by anybody. In his discussion of CoPs, 
Wenger notes that the notion of practice "is a level both of analysis and of experience" (1998: $126)$ - i.e. that it 'exists' at the level of practice, as well as at the level of analysis. This ontological claim surely cannot be made for 'configurations' that are 'removed from the scope of engagement' (above). It may be important to question the ontological status of these 'configurations': are they 'things' with real existence, or 'appearances'? It appears that configurations are 'continuities' between collections of objects, practices, styles and discourses (1998: 129) - the 'shared reifications' that different CoPs may have in common.

Although constellations of practice continue to carry the 'of practice' badge that appears to locate them firmly within a practice-based ontology, closer inspection reveals that they are a double abstraction: a reification of a reification. In this sense the continued use of the "-of practice' suffix offers potential for confusion, since it implies that 'constellations' are performed, when we can see that the construct has actually 'crept' two steps away from its practice-based root. Table 2 therefore shows the constellation of practice as an instance of ontological drift, in which the fallacy of processification has occurred - i.e. where semantic relationships with practice/process theory are invoked at epistemological level to discuss and explain a phenomenon that at root definition is actually an entity, being studied in the context of its relationships with other entities. As a result of this epistemic-ontological misalignment, the constellation of practice emerges as a markedly less coherent construct than the CoP.

Virtual Community of Practice (Dube et al., 2006). Dube et al.'s 'virtual community of practice' ( $\mathrm{vCoP})$ is arguably a further example of processification in which an entity is described using process terms. It is therefore another instance of ontological drift. The authors 
describe the vCoP as an organizational form "relying primarily on ICT to connect its members" (2006: 69-70) that no longer bears any trace of its root concept in Lave and Wenger's work. Although the $\mathrm{vCoP}$ continues to locate itself within the '-of practice' genre, the emergent, process-oriented ontology of Lave and Wenger's original concept has been replaced completely with an entitative ontology. Thus we see the creation of a typology of 21 structuring characteristics (2006: 69) for the creation of vCoPs, which is possible through "management decisions/actions that can be taken to assure the VCoP's success in view of a particular configuration" (2006: 88).

The vCoP framework appears to be a structuring typology leading to generic types, that leads in turn to specific configurations of generic types, finally generating management decisions and actions contingent upon these specific configurations of generic types. At the level of ontology, it is thus unclear in what sense vCoPs actually exist - i.e. whether vCoPs inhere in their status as an organizational form, in their membership, or in the ongoing, dynamic activity of their members. Table 2 therefore identifies the $\mathrm{vCoP}$ as a further example of ontological drift involving entitative definition and context at the level of ontology, but processoriented semantic relationships at the level of epistemology.

Inter-organizational Community of Practice (Moingeon et al., 2006). An interorganizational community of practice (IOCoP) is defined by Moingeon et al. as "an organizational form having autonomous governance, gathering voluntary individuals from different organizations, with a common professional practice and aiming at developing their expertise on an individual basis" (2006: 12). Moingeon et al. argue that although CoPs 
operating across organizations have been studied before, "IOCoPs do not represent a mere subcategory of CoPs, but a unit of analysis per se" (2006: 3, original italics). In spite of these entitative terms that encourage a view of IOCoPs as things, however, closer examination reveals inter-organizational CoPs to be an example of a process being described using entitative language: in this sense the opposite of the two previously discussed constructs, constellation of practice and vCoP, which were shown as entities being described using process language.

IOCoPs are processes described as entities because Moingeon et al. continue to recognise the heritage of CoPs and, by extension, the constitution of IOCoPs in social practice in a manner similar to Wenger (1998) - stressing especially the importance of socialisation and identification. Indeed, IOCoPs are in definition and context an expression of non-canonical, voluntary interactions around common problematics between people from different organizations, a dynamic phenomenon best discussed as a process as shown earlier in relation to the CoP. Table 2 therefore shows IOCoPs as an example of ontological drift in which reification has occurred. This is because a process perspective is taken in the definition and context of the phenomenon under study, but this is not aligned with the descriptive language used at epistemological level, which appears entitative - with the result that it is again unclear in what sense IOCoPs actually exist.

Insert Table 2 about here 
Network of Practice (Brown \& Duguid, 2000). In The Social Life of Information (2000), Brown and Duguid introduce the construct 'networks of practice' to denote groups of people where "most of the members are unknown to one another" and where links between members are "usually more indirect than direct...members coordinate and communicate through third parties or indirectly" (2000: 141-2). Although networks of practice are perhaps less explicitly entitative in emphasis than, for example, constellations of practice, which as shown earlier are "removed from the scope of engagement" (Wenger 1998: 126-7), they are markedly more entitative in nature than the CoP. Despite their name, networks of practice are not constituted from many CoPs, but directly (for example, the 25,000 reps working for Xerox are said directly to constitute a network), and discussed in contrast to more localised CoPs as an alternative 'type' of work-related network. Brown and Duguid's concept of a network of practice therefore has a very different ontological status from its 'root' concept in Situated Learning, and appears intended by its creators as a contrasting idea to the CoP, where LPP as identified by Lave and Wenger cannot possibly occur, since most members are unknown to one another.

Although a network of practice evolves, it clearly 'exists' in a more concrete, more entitative sense than the LPP dynamic from which CoPs are constituted, in a way that suggests for example that it might be mapped. In this case, a conscious ontological shift in focal definition and context of the phenomenon under study is accompanied by a corresponding shift in the semantic relationships claimed for the construct, which are distinguished clearly from those of the CoP. Table 2 therefore shows a clear abstraction towards a more entitative focus in which construct coherence and clarity is preserved through the continuing alignment of ontology and epistemology. 
Collectivity of Practice (Lindkvist, 2005). Finally, Lindkvist's 'collectivity of practice' shares the network of practice construct's concern with distributed knowledge in larger organizations, but focuses on the fleeting, more temporary character of many project-based associations, where people may work together for a short period of time to complete a task. Networks of practice are not communities but goal-oriented associations, in which various individuals draw on their own distributed sources of knowledge to contribute ideas and solutions to a 'market' where they may be adopted or discarded according to rationalist, objective assessment criteria. As noted by Lindkvist, such networks operate in a fundamentally different way from Wenger's CoP, which despite its structural focus nonetheless continues to invoke Lave and Wenger's dynamic of LPP: learning, identification, performance, increased recognition, further participation, and so on.

Lindkvist's paper breaks any lingering links with the practice perspective as outlined by Lave and Wenger - and indeed offers a thoughtful explanation of the limitations of this perspective for studying project teams in larger, distributed organizations. In similar manner to Brown and Duguid, Lindkvist is explicit about the sense in which the collectivity of practice can be said to exist: although it is temporary in nature, it is a definable association rather than an emergent dynamic, and locatable in the context of temporary, project-based associations. The shift in semantic relationships that this entails at the level of epistemology is made explicit, with a well-explained shift from a focus on knowledge-as-practice to individual knowledge, socialization to problem-solving, enculturated workers to free agents, and paradigm-driven understanding to the 'market' of goal-directed trial-and-error (2005: 1205). The collectivity of 
practice is therefore shown in Table 2 as a further example of ontological shift (abstraction) in which alignment between ontology and epistemology is successfully maintained, with resulting positive implications for construct coherence and clarity.

\section{A Genealogy of Difference}

Recalling the genealogy and taxonomy for whale and the shark, the genealogy of difference at Figure 5 uses the taxonomy at Table 2 to locate various 'descendant' constructs from Lave's Cognition in Practice, both historically and in terms of their degree of apparent relatedness. Broadly speaking, the further to the left a construct appears, the more process-oriented it appears to be; those constructs on the right are broadly entitative in focus. The additional examples of Lave (1993) and Hadley (2006), are not new constructs that extend the '-of practice' label, but are included as examples of related literature that continues within Lave's process-oriented worldview, and therefore where little or no ontological shift or drifts has occurred. For reasons of space these are included merely as referents, rather than subjected to detailed analysis.

Unlike biological genealogies, the intention here is of course not to argue that constructs are literally related (for example, that Brown and Duguid (2000)'s network of practice was the direct inspiration behind Lindkvist (2005)'s collectivity of practice) but to expose similarities and differences, however arrived at, between various apparently closely related constructs as these have appeared over time. Thus, for example, although Lave and Wenger's (1991) Community of Practice (1) and Dube et al. (2006)'s Virtual Community of Practice (underlined in both Table 2 and Figure 5) appear superficially related, we can see the extent to which each 
actually rests on a very different ontological claim and supporting epistemological framework. Finally, it is noticeable that examples of ontological shift appear at both left (process) and right (entity) sides of the tree in Figure 5, with examples of ontological drift towards the middle of the tree - further underlining the argument made in this paper that the effectiveness of a construct lies less in the worldview it adopts than the transparency with which it does so.

Insert Figure 5 about here

\section{IMPLICATIONS FOR THEORY AND PRACTICE}

\section{Four implications for researchers}

The preceding discussion and empirical analysis holds several implications for organizational theory and practice. There are four implications for researchers. The first is that conscious, playful shifting of a construct's relative positioning along the ontological spectrum between process and entity can constitute a richly generative methodology for theory generation. By the same token, however, the use of a construct in a different, unacknowledged positioning along this spectrum carries the risk of an unmooring, or drift, between this new ontological position and its supporting epistemological framework, with a negative impact on construct clarity. 
The second implication, which derives closely from the first, is that it is necessary for researchers to maintain a constant awareness of the need for epistemic-ontological alignment within all of the constructs with which they engage; it is hoped that the framework developed in this paper may provide some assistance in this regard.

The third implication is that a systematic awareness of the four types of possible epistemicontological movement as set out in Figure 2 allows the researcher to ask her/himself certain questions that will improve the clarity of resulting constructs. For example, when abstracting a concept from the flow of experience (the 'snapshots' of the pseudopod in Figure 1, or the organogram), are we merely relabeling a process as a noun (reification), or are we describing something with a different, more 'standalone' ontological status, context, and semantic relationships, increased generalisability, and reduced local specificity? Similarly, when reframing an entity as a process ('person' becomes 'person in action'; 'encoded knowledge' becomes 'embodied knowledge', 'strategy' becomes 'strategy as practice'), are we merely relabeling a noun as a process (processification), or are we taking into account the conjunctive implications of such a shift in terms of acknowledging its emergence over time, its connectedness with other entities or concepts, or its limited generalisability across other organizations? As researchers, we can ask these, and other similar questions, about our work whether we are consciously attempting an ontological shift, or merely trying to ensure avoidance of ontological drift. Some further useful questions arising from this methodology are set out in Table 3 . 
The fourth implication for researchers is that the construct clarity-taxonomy-genealogy methodology used here has shown itself to be a useful way of revealing important differences in epistemic-ontological alignment between apparently similar-sounding constructs within a single genre of organizational literature. This being the case, it may be that such a methodology might be systematically applied to other clusters of related constructs, with equally revealing results. As well as offering a potentially useful tool for generating clear, new theory, therefore, the framework presented here allows a new way in which to assess critically the landscape of existing theory.

\section{Two Implications for Practice}

For practitioners seeking to operationalise a construct within the organizational environment, there are two linked implications. First, practitioners should be aware that a construct's epistemic-ontological positioning is likely to offer certain benefits, as well as drawbacks, in each case. Entitative constructs are likely to be more easily implemented, controlled and measured, and are thus potentially attractive to managers who may be under pressure to deliver predicted outcomes and minimise unexpected consequences. However, more conjoined, process-oriented constructs are likely to promise an engagement with a more socially embedded side to organizational life that is likely to hold greater personal relevance and motivational power for workers - but prove more difficult to predict and control, which may be less attractive to managers. As discussed earlier, a trade-off is necessarily required between the two extremes, and it is important that practitioners understand the likely benefits and compromises in each case. 
For example, we can see immediately that the of CoP/LPP construct (Lave \& Wenger 1991) described earlier as a delicate dynamic achievable in certain localised instances (represented in quadrant 2 in Figure 2) may hold some attractiveness to organizations, since it holds the promise of creating groups of highly motivated workers capable of sharing knowledge very effectively. However, such groups cannot necessarily be replicated in large organizations simply by creating canonical organizational constructs called 'communities of practice' (quadrant 3 in Figure 2); in such cases, all that will have been created is an entity that appears to be a process (processification). Instead, organizational implementation of the CoP/LPP construct is likely to require a more sophisticated approach involving a careful balance between local autonomy and management control (Thompson 2005). The CoP examples demonstrate that an appreciation of the epistemic-ontological alignment of a construct will indicate whether it is likely to be transferable in a relatively unproblematic way into the organizational context. More entitative constructs are likely to be more straightforward for organizations to create and support than constructs that are more process-oriented. As a result, organizations would do well to look closely at whether the benefits attributed to a construct are likely to be replicable within their own environments.

As a consequence, the second implication for practitioners is the need for an awareness that managers who hold organizational accountability may find it difficult to implement and report the effectiveness of process constructs in meaningful ways, since they may be required to express themselves using primarily entitative terms that promise greater stability and control (Chia \& Holt, 2008: 142). As a result, it is possible that more entitative constructs may hold 
greater natural appeal to organizations - or, where organizations implement process-oriented constructs, that managers may feel it more appropriate to discuss and report on these using entitative terminology. Examples of such a possible 'entitative bias' discussed in this paper include the organizational trend towards adoption of best practices, common standards, and professional codes, the 'harvesting' of tacit knowledge, and the progressively canonical, entitative way in which Lave (1988) and Lave and Wenger's (1991) initial, process-oriented ideas have been expressed and discussed within organizations (Contu \& Willmott, 2002; Kimble, 2006).

There is broad acceptance amongst both researchers and practitioners of the need to achieve greater mutual relevance between the two communities (Abrahamson, 1996; Rynes, Bartunek, \& Daft 2001), which, if it is shown to exist, an entitative bias of the type outlined above can only inhibit. This is because organizations showing entitative bias may be likely to adopt only those research constructs that are entitative in nature, or to harbour simplistic expectations about the ease with which these may be implemented - or simply to misunderstand more process-oriented research constructs, and reject them altogether. It would therefore seem a worthwhile activity to conduct an empirical investigation of the possible existence of entitative bias within the organizational world. Such an investigation might comprise a systematic mapping of the epistemic-ontological alignment of those management constructs that have enjoyed particular popularity within the practitioner community, in which the testable hypothesis is that organizations display particular susceptibility towards those more abstractable constructs that promise greater ownership, and control. 
Table 3 draws together these implications for into a set of questions intended to enable researchers and practitioners to take advantage of an enhanced awareness of ontological shift and drift in their own work. The questions reflect Suddaby's (2010) framework for construct clarity used throughout the paper, and offer a simple test for both audiences to ensure that they do not fall foul of the various pitfalls that have been described. The first column of Table 3 is intended for researchers seeking to generate or enhance theory via a 'playful reframing' of a construct along the lines illustrated here. The questions encourage the building of a genealogical sense of the relative position of a reframed construct in relation to the landscape of similar constructs, enabling a more articulate explanation of the purpose and benefits of an ontological abstraction/conjunction, as well as a check for contextual appropriateness. They also enable a more knowing attentiveness to epistemological alignment, and overall coherence.

The second column of Table 3 is intended for researchers who may simply seek to re-use and apply an existing construct within their own research. In this case, the questions are intended to ensure that the existing definition of the construct is consistent with the context in which it is being applied, and that inappropriate properties are not being claimed for the phenomenon that do not exist in reality. Drawing on the earlier discussion of the CoP canon, an example might be a discussion of the CoP (Lave \& Wenger 1991) in an entitative sense as a 'thing', or the attribution of the socially embedded, emergent properties characteristic of a CoP to, say, a project team, or network of practice. In each case, the researcher would be committing an epistemic-ontological fallacy: the former is an example of reification, or describing processes as entities, whereas the latter is an example of processification, or describing entities as processes. 
The third column of Table 3 lists several questions for practitioners seeking to operationalise concepts from management research within organizations. The questions correspond closely with those suggested for researchers, but are intended to help organizations to avoid simplistic treatment of management concepts as 'magic bullets' to be transferred unproblematically into the organizational context. Here, there is an emphasis on ensuring that there is a close understanding of the ontological status of a management construct, and thus a realistic appreciation of the manner and extent to which the construct should be supported - as well as of the benefits that may reasonably be expected; benefits are especially unlikely to be realised in instances of reification or processification. Finally, a question specifically encourages organizations to consider their motives for selecting a particular construct: in particular, whether these may have been clouded by any form of entitative bias, in which a construct may be favoured because it appears to offer greater resonance with a discourse of ownership and control.

Insert Table 3 about here

\section{CONCLUDING COMMENTS}

Whether consciously seeking to develop new theory, use existing theory, or apply theory within organizations, it is hoped that the concepts of ontological shift and ontological drift, and the four types of epistemic-ontological movement that underlie these, may support readers in 
furthering $A M R$ 's mission in developing new theoretical insights that advance our understanding of management and organizations (LePine \& King, 2010). In addition, the concepts outlined and illustrated here may assist not only the way in which the management research community generates and evaluates good theory, but also the way in which theory is explained to, and interpreted, and evaluated by, organizations. Achieving clarity about the ontological claims we make for our constructs - where, and in what sense, these are said to exist - must surely constitute a central aim for all those who work within our field.

Finally, it is hoped that addressing a long standing, often fairly polarized debate within management studies in a novel way may have helped in the ongoing work to build a more inclusive research field capable of engaging with both entitative and process-oriented dimensions within a single construct. Indeed, it should be possible for readers to apply the framework presented in Figure 2 together with the evaluative framework in Table 3 to conduct and assess their own 'playful' ontological reframing. In undertaking such an exercise, readers may in turn highlight areas of epistemological clarity, as well as revealing some of the epistemological blindspots, in their own research. 


\section{REFERENCES}

Abrahamson, E. G. 1996. Management Fashion. Academy of Management Review, 21(1): 254285.

Adler, P. S., \& Kwon, S-W. 2002. Social capital: Prospects for a new concept. Academy of Management Review, 27(1): 27-40.

Alvesson, M., \& Willmott, H. 2002. Identity Regulation as organizational control: Producing the appropriate individual. Journal of Management Studies, 39(5): 619-642.

Bakken, T., \& Hernes, T. 2006. Organizing is both a verb and a noun. Organization Studies, 27(11): 1599-1616.

Blackler, F. 1995. Knowledge, Knowledge Work and Organizations: An Overview and Interpretation. Organization Studies, 16(6): 1021-1046.

Bourdieu, P. 1977. Outline of a theory of practice. Trans. R. Nice. Cambridge: Cambridge University Press.

Burgelman, R. A. 2009. Combining Grounded Theorizing and Historical Methods: A Proposal to Strengthen the Power of Qualitative Research. Research paper 2045, Stanford Research Paper Series.

Brown, J. S., \& Duguid, P. 2000. The social life of information. Boston: Harvard Business School Press.

Carlsen, A. 2006. Organizational becoming as dialogic imagination of practice: The case of the indomitable Gauls. Organization Science, 17(1): 132-149.

Carlson, S. J. 1999. Evolution: Investigating the evidence. Paleontological Society Special Publication, 9. http://www.ucmp.berkeley.edu/education/events/carlson2.html.

Chia, R. 2002. Essai: Time, duration and simultaneity: Rethinking process and change in organizational analysis. Organization Studies, 23(6): 863-868.

Chia, R. 2007. Essai: Thirty years on: From organizational structures to the organization of thought. Organization Studies, 18(4): 685-707.

Chia, R., \& Holt, R. 2008. On managerial knowledge. Management Learning, 39(2): 141-148.

Cooke, B. \& Kothari, U. 2001. Participation: The new tyranny? New York: Zed Books.

Contu, A., \& Willmott, H. 2002. Reclaiming knowledge: Situated learning theory revisited. Working Paper 0105, Manchester School and Management, Manchester School of Management, Manchester.

Darwin, C. 1837-8. Notebook B, transmutation of species. Cambridge: University of Cambridge Library. 
Davenport, T., and Prusak, L. 2000. Working Knowledge. Boston: Harvard Business School Press.

DiMaggio, P. J., \& Powell, W. W. 1983. The iron cage revisited: Institutional isomorphism and collective rationality in organizational fields. American Sociological Review, 48(2): 147160 .

Douglas, M. 1986. How institutions think. London: Routledge and Kegan-Paul.

Dube, L., Bourhis, A., \& Jacob, R. 2006. Towards a typology of virtual communities of practice. Interdisciplinary Journal of Information, Knowledge and Management, 1: 69-92.

Dupouet, O., \& Yildizoglu, M. 2006. Organizational performance in hierarchies and communities of practice. Journal of Economic Behaviour and Organization, 61: 668690.

Feldman, M. 2000. Organizational routines as a source of continuous change. Organization Science, 11(6): 611-629.

Fox. S. 2000. Communities of practice, Foucault and actor-network theory. Journal of Management Studies, 37(6): 853-867.

Garrety, K., Robertson, P. L., \& Badham. R. 2004. Integrating communities of practice in technology development projects. International Journal of Project Management, 22: 351-358.

Giddens, A. 1979. Central problems in social theory: Action, structure, and contradiction in social analysis. Berkeley: University of California Press.

Hall, P. A., \& Taylor, R.C.R. 1996. Political science and the three new institutionalisms. Political Studies, 44: 952-973.

Hassard, J. 1993. Sociology and organization theory: Positivism, paradigm and postmodernity. Cambridge: Cambridge University Press.

Jarzabkowski, P. \& Spee, A. P. 2009. Strategy as practice: A review and future directions for the field. International Journal of Management Reviews, 11(1): 69-95.

Johnson, G., Langley, A., Melin, L., \& Whittington, R. 2007. Strategy as Practice. Cambridge: Cambridge University Press.

Kim, S. C. 2005. Nested institutions and the retardation of the adaptive process. Systems Research and Behavioural Science, 22(6): 483-495.

Kimble, C. 2006. Communities of Practice: Never knowingly undersold. Paper presented at the EC-TEL 2006 Workshops, Crete, Greece. 
Kimble, C., \& Hildreth P. 2004. Communities of practice: Going one step too far?. Proceedings 9è colloque de l'AIM, Evry, France.

Lave, J. 1988. Cognition in practice. Cambridge: Cambridge University Press.

Lave, J. 1993. The practice of learning. In S. Chaiklin, \& J. Lave (Eds.), Understanding practice: Perspectives on activity and context: 3-32. Cambridge: Cambridge University Press.

Lave, J., E. Wenger. 1991. Situated learning: Legitimate peripheral participation. Cambridge: Cambridge University Press.

Lefevbre, H. 2004. Rhythmanalysis: Space, Time and Everyday Life. London: Continuum.

LePine, J.A., \& King, A. W. 2010. Editors' comments: Developing novel theoretical insight from reviews of existing theory and research, Academy of Management Review, 35(4): 506-509.

Lesser, E. L., \& Storck, J. 2001. Communities of practice and organizational performance. IBM Systems Journal, 40(4).

Lindkvist, L. 2005. Knowledge communities and knowledge collectivities: A typology of knowledge work in groups. Journal of Management Studies, 42(6): 1189-1210.

Lowe, K. B., \& Gardner, W. L. 2000. Ten years of the Leadership Quarterly: Contributions and challenges for the future. Leadership Quarterly, 11: 459-514.

Lukács, G. 1969. Reification and the consciousness of the proletariat. In G. Lukács, History \& Class Consciousness: 240-69. New York: Pegasus.

March, J. G., and Olsen, J. P. 1989. Rediscovering institutions: The organizational basis of politics. New York: Free Press.

Mahony, K. 2003. The politics of professionalisation: Some implications for the occupation of ambulance paramedics in Australia. Journal of Emergency Primary Health Care, 1(3-4): Article No. 990044.

MacCallum, R. C., \& Austin, J. T. 2000. Applications of structural equation modeling in psychological research. Annual Review of Psychology, 51: 201-226.

McDermott, R. 1999. Why information technology inspires but cannot deliver knowledge management. California Management Review, 41(4): 103-117.

McKelvey, B. 2003. Postmodernism vs. Truth in Management Theory. In E. Locke, (Ed.), Post Modernism and Management: Pros, Cons and the Alternative. Research in the Sociology of Organizations, 21: 113-168. Amsterdam, NL: Elsevier Science.

Merton, R. K. 1949. Social Theory and Social Structure. New York: The Free Press. 
Moingeon, B., Quelin, B., Dalsace, F., \& Lumineau, F. 2006. Inter-organizational communities of practice: Specificities and stakes. Les Cahiers de recherche, 857.

National Health Service. 2005. Knowledge harvesting: What is knowledge harvesting? NHS Evidence: Knowledge Management, UK: http://www.library.nhs.uk/knowledgemanagement/ViewResource.aspx?resID=93815.

Nonaka, I., \& Takeuchi, H. 1995. The Knowledge-Creating Company: How Japanese Companies Create the Dynamics of Innovation. New York: Oxford University Press.

North, D. 1990. Institutions, Institutional Change, and Economic Performance. Cambridge: Cambridge University Press.

Orr, J. 1996. Talking about machines: An ethnography of a modern job. Ithaca, NY: Cornell University Press.

Pan, S. L., \& Leidner, D. E., 2003. Bridging communities of practice with information technology in pursuit of global knowledge sharing. Journal of Strategic Information Systems, 12: 71-88.

Polanyi, M. 1966. The Tacit Dimension. London: Routledge.

Pugh, K., and Dixon, N. M. 2008. Don't just capture knowledge - put it to work. Harvard Business Review, The Magazine, May issue, http://hbr.org/2008/05/dont-just-captureknowledge-put-it-to-work/ar/1.

Pugh, D., Hickson, D., and Hinings, R. 1986. Writers on Organization. Harmondsworth: Penguin.

S Rashid, S., Masood, T., \& Weston, R. H. Unified modelling in support of organization design and change. Proceedings of the Institution of Mechanical Engineers, Part B: Journal of Engineering Manufacture, 223(8): 2041-2975.

Reiser, R. A., \& Dempsey, J. V. (Eds.). 2007. Trends and Issues in Instructional Design and Technology (2nd ed.). Saddle River, NJ: Pearson Education.

Rogers, E. M. 1962. Diffusion of innovations. New York: Free Press.

Rynes, S. L., Bartunek, J. M., \& Daft, R. L. 2001. Across the great divide: Knowledge creation and transfer between practitioners and academics. Academy of Management Journal 44(2): 340-355.

Sarbin, T. R.. 1966. Role Theory. In B. J. Biddle \& E. J. Thomas (Eds.), Role Theory: Concepts and Research. New York: John Wiley \& Sons.

Schatzki, T. 2001. Introduction: Practice Theory. In: T. Schatzki, K. Knorr Cetina and E. von Savigny (Eds.), The Practice Turn in Contemporary Theory: 1-14. London: Routledge. 
Sturdy, A. 2003. Knowing the unknowable? A discussion of methodological and theoretical issues in emotion research and organizational studies. Organization, 10(1): 81-105.

Suddaby, R. 2010. Construct clarity in theories of management and organization. Academy of Management Review, 35(3): 346-357.

Swan, J., Scarborough, H, \& Robertson, M. 2002. The construction of 'communities of practice' in the management of innovation. Management Learning, 33(4): 477-496.

Thompson, M. 2005. Structural and epistemic parameters in communities of practice. Organization Science, 16(2): 151-164.

Tsoukas, H. 1996. The firm as distributed knowledge system: A constructionist approach. Strategic Management Journal, 17 (Winter Special Issue): 11-25.

Tsoukas, H, and R. Chia. 2002. On Organizational Becoming: Rethinking Organizational Change. Organization Science, 13(5): 567-582.

Van Foerster, H. 1967. Time and memory. Annals of the New York Academy of Sciences 138(Article 2): 866-873.

Van Maanen, J., Sorensen, J.B., and Mitchell, T.R. 2007. Introduction to special topic forum: The interplay between theory and method. Academy of Management Review, 32(4): 11451154.

Von Krogh, G., Ichijo, K., and Nonaka, I. 2000. Enabling Knowledge Creation. Oxford: Oxford University Press.

Weick, K. E., 1989. Theory Construction as Disciplined Imagination. Academy of Management Review, 14(4): 516-531.

Weick, K. 1969. The Social Psychology of Organizing. Reading, MA: Addison-Wesley.

Wenger, E. 1998. Communities of practice: Learning, meaning, and identity. Cambridge: Cambridge University Press.

Wertsch, J. V. 1985. Vygotsky and the social formation of mind. Cambridge, Mass.: Harvard University Press.

Whitehead, A. N. 1925. Science and the modern world. Free Press (Simon \& Schuster).

Whittington, R. 2003. The work of strategizing and organizing: For a practice perspective. Strategic Organization, 1: 117-125.

Wilson, D. C., \& Rosenfeld, R. H. 1990. Managing organizations: Text, readings, and cases. London and New York: McGraw-Hill.

$\mathrm{Xu}$, L. 2007. Outsourcing and Multi-Party Business Collaborations Modeling. Journal of Electronic Commerce in Organizations, 5(2): 77-96. 
TABLE 1: Taxonomy of character states (from Carlson 1999)

\begin{tabular}{|c|c|c|c|c|c|c|c|c|c|c|}
\hline $\begin{array}{l}\text { Character } \\
\text { States }\end{array}$ & $\frac{n}{\bar{E}}$ & $\stackrel{\Xi}{\Xi}$ & $\stackrel{0}{0}$ & 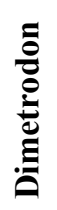 & 胥 & $\frac{\frac{0}{J}}{\frac{\pi}{3}}$ & $\begin{array}{l}\stackrel{0}{0} \\
: \\
\stackrel{0}{0} \\
\stackrel{0}{0}\end{array}$ & 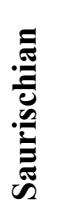 & 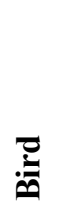 & 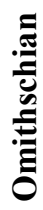 \\
\hline 1. Vertebral column & + & + & + & + & + & + & + & + & + & + \\
\hline 2. Bony internal skeleton & & + & + & + & + & + & + & + & + & + \\
\hline 3. 4 limbs; 5 fingers $\&$ toes & & & + & + & + & + & + & + & + & + \\
\hline 4. Lower temporal fenestra & & & & + & + & + & + & + & + & + \\
\hline 5. Upper temporal fenestra & & & & & & & + & + & + & + \\
\hline 6. Antiorbital fenestra & & & & & & & + & + & + & + \\
\hline 7. Amniotic egg & & & & $?$ & + & + & + & $?$ & + & $?$ \\
\hline 8. Mammary glands & & & & $?$ & + & + & & $?$ & & $?$ \\
\hline 9. Endothermy & & & & $?$ & + & + & & $?$ & + & $?$ \\
\hline 10. Reduced $4^{\text {th }} \& 5^{\text {th }}$ digits & & & & & & & & + & + & + \\
\hline 11. Fully upright posture & & & & & & & & + & + & \\
\hline 12. Long S-shaped neck & & & & & & & & + & + & \\
\hline 13. Long hands & & & & & & & & & + & + \\
\hline 14. "Bird-hipped" pelvis & & & & & & & & & & \\
\hline
\end{tabular}


TABLE 2

Taxonomy of Epistemic-ontological Alignment and Resulting Construct Clarity

\begin{tabular}{|c|c|c|c|c|c|c|c|c|}
\hline $\begin{array}{l}\text { Taxa } \\
\\
\text { Dimensions } \\
\text { of construct } \\
\text { clarity } \\
\text { (Suddaby } \\
\text { 2010) }\end{array}$ & $\begin{array}{l}\text { Cognition in } \\
\text { practice (Lave } \\
1988 \text { ) }\end{array}$ & $\begin{array}{l}\text { Community of } \\
\frac{\text { Practice (1) }}{\text { (Lave \& }} \\
\underline{\text { Wenger 1991) }}\end{array}$ & $\begin{array}{l}\text { Community of } \\
\text { practice (2) } \\
\text { (Wenger 1998) }\end{array}$ & $\begin{array}{l}\text { Constellation of } \\
\text { practice (Wenger } \\
1998 \text { ) }\end{array}$ & $\begin{array}{l}\text { Virtual community } \\
\text { of practice (Dube } \\
\text { et al 2006) }\end{array}$ & $\begin{array}{l}\text { Inter-organizational } \\
\text { community of } \\
\text { practice (Moingeon } \\
\text { et al 2006) }\end{array}$ & $\begin{array}{l}\text { Network of } \\
\text { practice (Brown } \\
\text { \& Duguid } \\
\text { 2000) }\end{array}$ & $\begin{array}{l}\text { Collectivity of } \\
\text { practice } \\
\text { (Lindkvist } \\
2005 \text { ) }\end{array}$ \\
\hline Definition & $\mathbf{P}$ & $\mathbf{P}$ & $\mathbf{P} / \mathbf{E}$ & $\mathbf{E}$ & $\mathbf{E}$ & $\mathbf{P}$ & $\mathbf{E}$ & $\mathbf{E}$ \\
\hline Context & $\mathbf{P}$ & $\mathbf{P}$ & $\mathbf{P} / \mathbf{E}$ & $\mathbf{E}$ & $\mathbf{E}$ & $\mathbf{P}$ & $\mathbf{E}$ & $\mathbf{E}$ \\
\hline $\begin{array}{l}\text { Semantic } \\
\text { relationships }\end{array}$ & $\mathbf{P}$ & $\mathbf{P}$ & $\mathbf{P} / \mathbf{E}$ & $\mathbf{P}$ & $\mathbf{P}$ & $\mathbf{E}$ & $\mathbf{E}$ & $\mathbf{E}$ \\
\hline \multirow[t]{3}{*}{ Coherence } & $\mathrm{Y}$ & $\mathrm{Y}$ & $\mathrm{Y}$ & $\mathrm{N}$ & $\mathrm{N}$ & $\mathrm{N}$ & $\mathrm{Y}$ & $\mathrm{Y}$ \\
\hline & $\begin{array}{l}\text { Ontological } \\
\text { shift: }\end{array}$ & $\begin{array}{l}\text { Ontological } \\
\text { stasis }\end{array}$ & $\begin{array}{l}\text { Ontological } \\
\text { shift: }\end{array}$ & $\begin{array}{l}\text { Ontological } \\
\text { drift: }\end{array}$ & $\begin{array}{l}\text { Ontological } \\
\text { drift: }\end{array}$ & $\begin{array}{l}\text { Ontological } \\
\text { drift: }\end{array}$ & $\begin{array}{l}\text { Ontological } \\
\text { shift: }\end{array}$ & $\begin{array}{l}\text { Ontological } \\
\text { shift: }\end{array}$ \\
\hline & Conjunction & & Abstraction & Processification & Processification & Reification & Abstraction & Abstraction \\
\hline
\end{tabular}


TABLE 3

Ensuring Epistemic-ontological Alignment: An Evaluative Framework

\begin{tabular}{|c|c|c|c|}
\hline $\begin{array}{r}\text { Scenario } \\
\text { Type of question }\end{array}$ & $\begin{array}{l}\text { Researchers attempting } \\
\text { ontological shift }\end{array}$ & $\begin{array}{l}\text { Researchers avoiding ontological } \\
\text { drift }\end{array}$ & $\begin{array}{l}\text { Organizations implementing } \\
\text { management ideas }\end{array}$ \\
\hline Definition & $\begin{array}{l}\text { Is there an opportunity to generate } \\
\text { new theoretical perspectives via an } \\
\text { ontological reframing? } \\
\text { Where might such a reframed } \\
\text { construct be located in Figure } 2 \text { in } \\
\text { relation to any existing constructs? } \\
\text { What are the benefits and limitations } \\
\text { of such (a further) } \\
\text { abstraction/conjunction? }\end{array}$ & $\begin{array}{l}\text { What is the nature of the phenomenon } \\
\text { under study? } \\
\text { What claims are being made for it at the } \\
\text { ontological level? In what sense can it } \\
\text { be said to exist? } \\
\text { Is this definition consistent with } \\
\text { previous usage of the construct? }\end{array}$ & $\begin{array}{l}\text { Is the phenomenon a thing that the } \\
\text { organization can create, own, and } \\
\text { control? Is it an entity to be built, or a } \\
\text { behavioural process to be cultivated? } \\
\text { What is the extent of its interlinkage } \\
\text { with/dependency on other phenomena? } \\
\text { Where can the phenomenon be said to } \\
\text { exist, e.g. in physical structures, group } \\
\text { behaviour, or peoples' heads? }\end{array}$ \\
\hline Context & $\begin{array}{l}\text { Does the empirical context support } \\
\text { such an attempt? Is it practical? }\end{array}$ & $\begin{array}{l}\text { Is the definition appropriate to the } \\
\text { empirical context? }\end{array}$ & $\begin{array}{l}\text { Have the more context-dependent/risky } \\
\text { aspects of implementing the construct } \\
\text { been underestimated? }\end{array}$ \\
\hline $\begin{array}{l}\text { Semantic } \\
\text { relationships }\end{array}$ & $\begin{array}{l}\text { What sort of concepts, supporting } \\
\text { frameworks and language will be } \\
\text { required to support the construct at } \\
\text { epistemological level? } \\
\text { Will it be necessary to draw upon an } \\
\text { adjacent literature for these? }\end{array}$ & $\begin{array}{l}\text { Are the concepts, supporting } \\
\text { frameworks and language an } \\
\text { appropriate lens through which to view } \\
\text { the phenomenon? } \\
\text { Are entitative terms being used to } \\
\text { describe processes (reification), or } \\
\text { process terms used to describe entities } \\
\text { (processification)? }\end{array}$ & $\begin{array}{l}\text { Are entitative terms being used to } \\
\text { describe processes (reification), or } \\
\text { process terms used to describe entities } \\
\text { (processification)? } \\
\text { Is any unconscious entitative bias } \\
\text { present in the selection of this construct? }\end{array}$ \\
\hline Coherence & \multicolumn{3}{|c|}{$\begin{array}{l}\text { Is there any lingering, residual inconsistency between the ontological focus, empirical context, and the terms and } \\
\text { associated theoretical constructs being used to describe/discuss these? }\end{array}$} \\
\hline
\end{tabular}


FIGURE 1

The Pseudopod: "Entity is Not Just Entity and Movement is Not Just Movement" (Van Foerster 1967, in Bakken \& Hernes 2006)

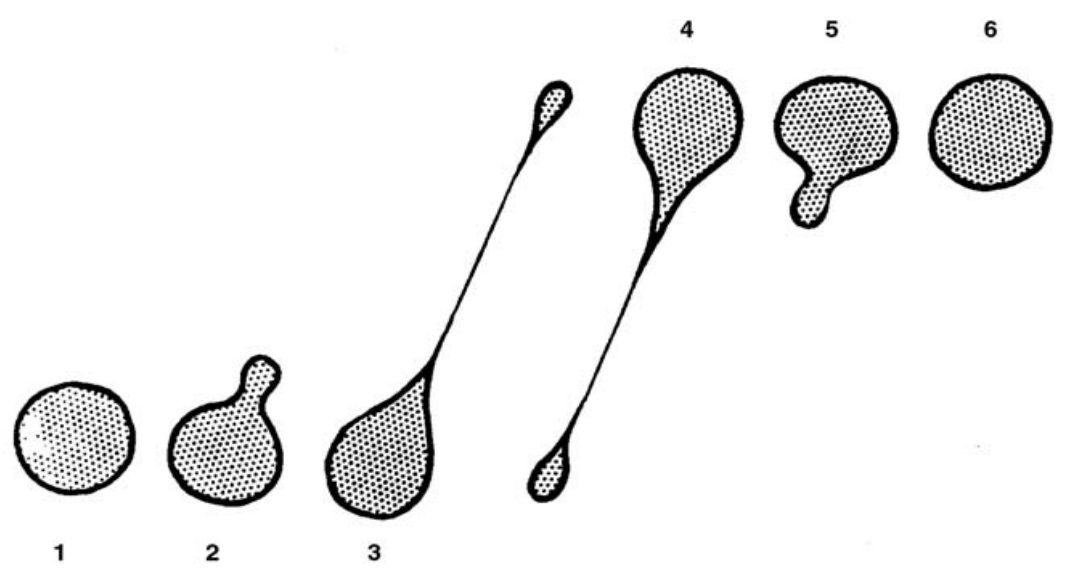


FIGURE 2

Ontological shift or ontological drift? A typology for maintaining construct clarity

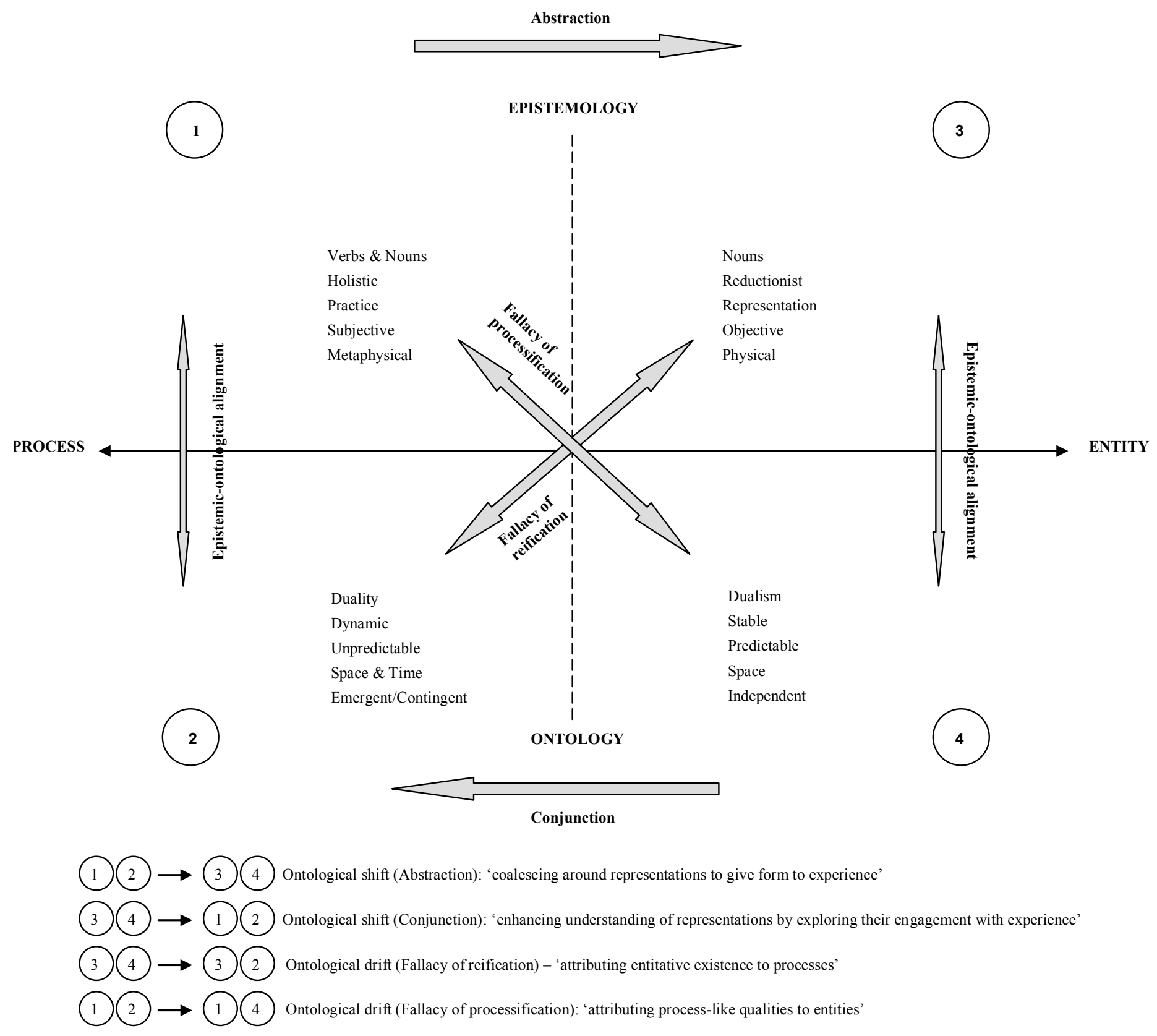


FIGURE 3

Darwin's Tree of Life Sketch, taken from Notebook B (1837-8) (University of Cambridge Library)

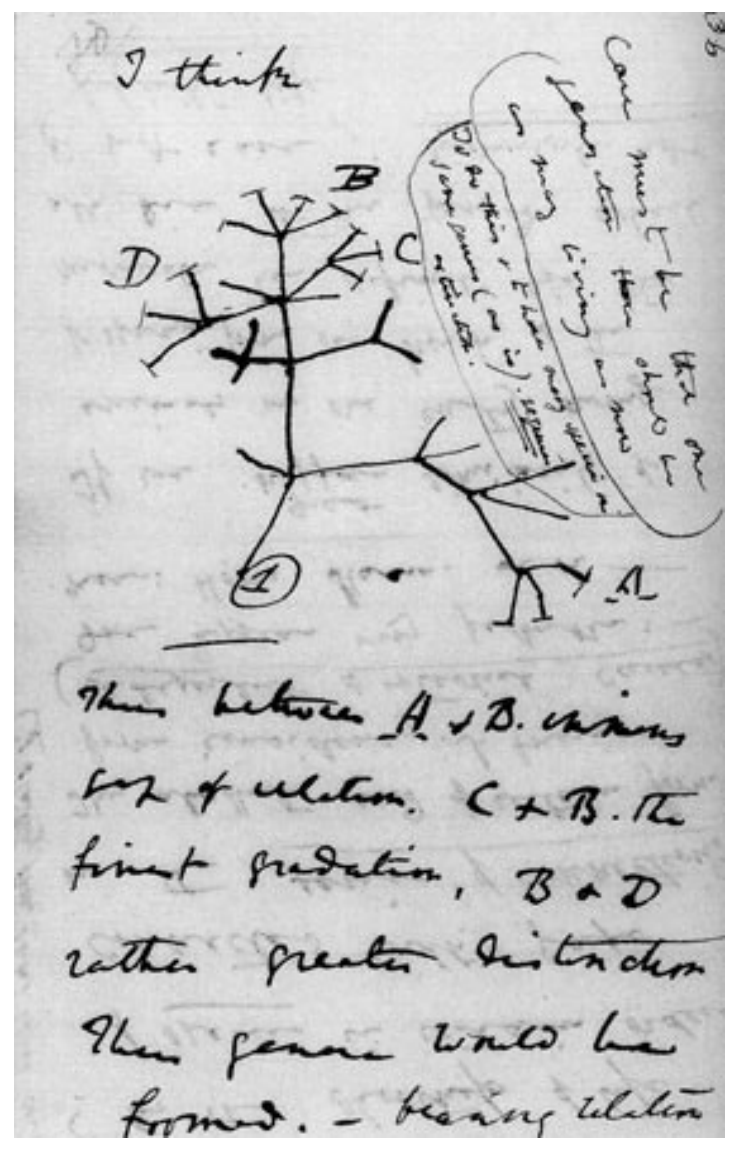


FIGURE 4

Defying Appearances: Are Whales Closer to Sharks, or to Humans? Phylogenetic Tree (from Carlson 1999)

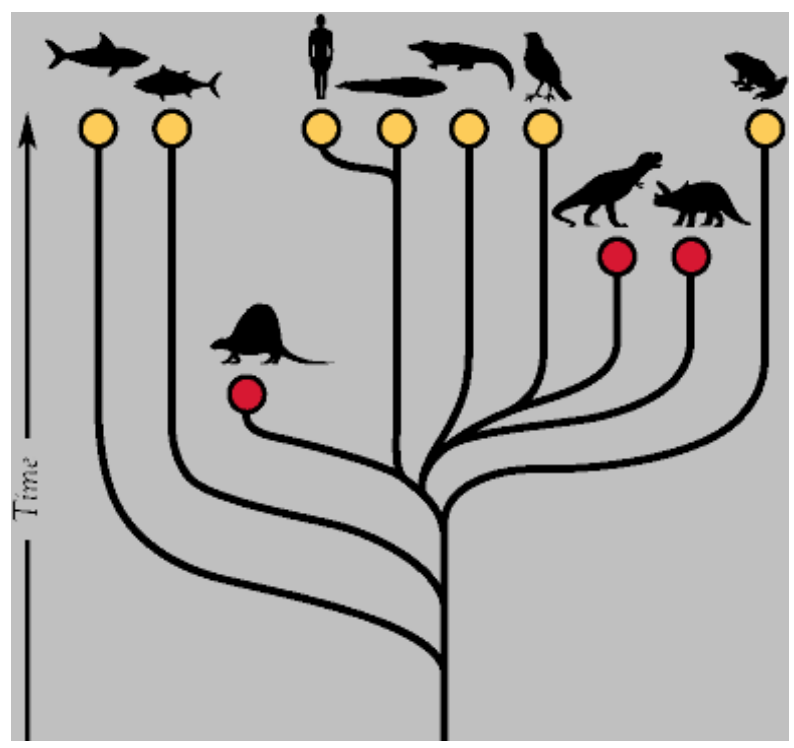


FIGURE 5

Defying Appearances: Are the CoP and vCoP related Constructs? Genealogical Tree
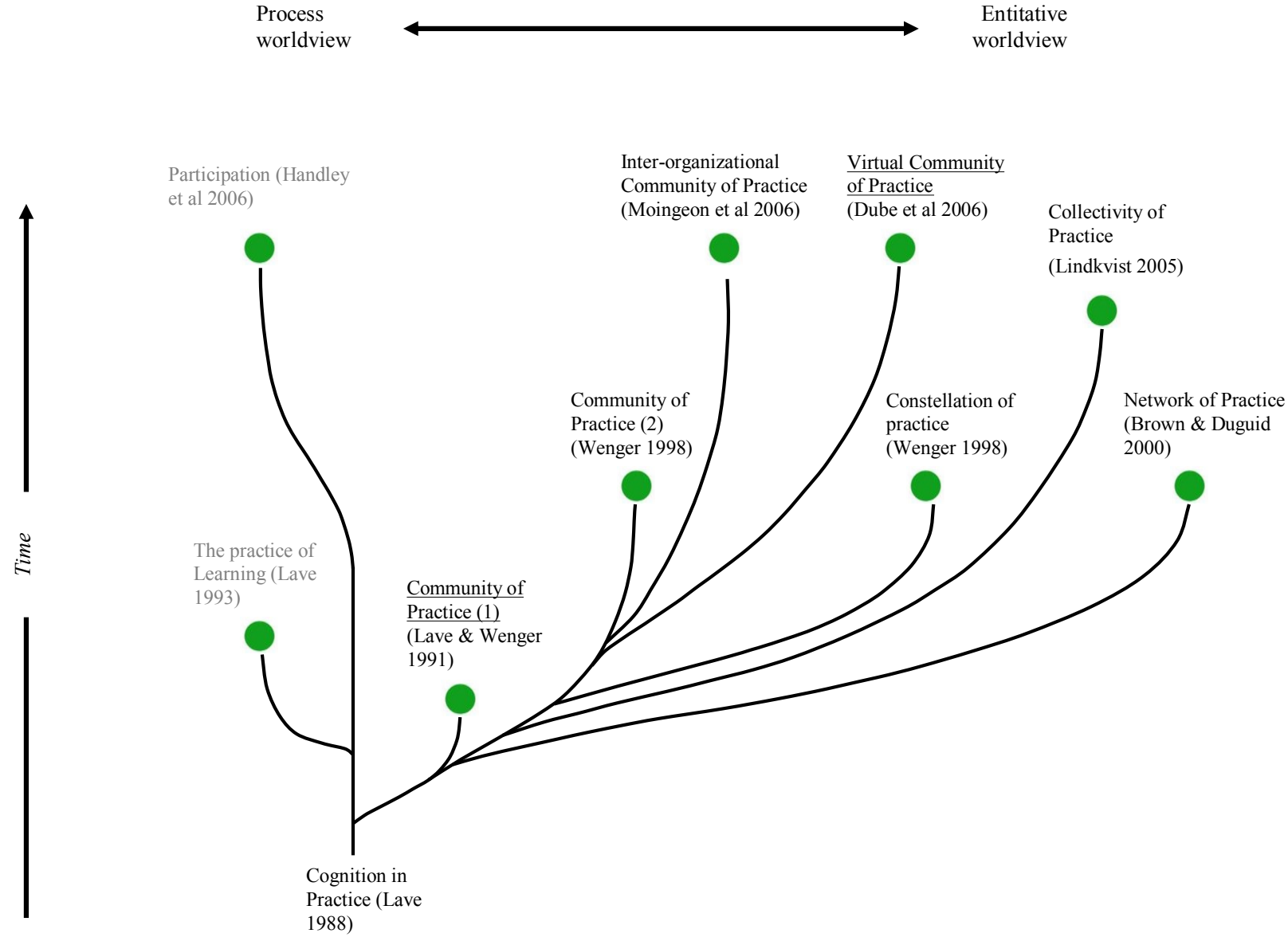
Mark Thompson is a lecturer in information systems at Cambridge University, and director of Methods Consulting, a London-based business and IS consulting firm. He received his Ph.D from Cambridge University in 2003. His current research interests include process-based theoretical perspectives on work, identity, and social organization. 